\title{
China's new AIDS policy faces great wall of skepticism
}

China has finally announced its decision to act on its impending AIDS crisis, but experts say its strategy is in many ways premature and poorly planned.

Official estimates place the number of HIVpositive people in China at 840,000 , which is relatively low for a population of 1.2 billion. Most cases are from high-risk groups such as intravenous drug users, prostitutes, long-distance truck drivers and plasma sellers, often in isolated rural areas. But the numbers are rising dramatically, with a $44 \%$ increase between 2001 and 2002, and the epidemic is starting to spread to urban areas. At the current rate, the United Nations (UN) projects 10-20 million cases in China by the year 2010 .

Faced with that specter and the shortcomings of its long-neglected health system, made evident by SARS, the Chinese government in early 2003 launched an ambitious plan to train doctors, build 124 new treatment centers, increase awareness and deliver treatment and counseling to patients in 56 of the country's hardest-hit counties.

As part of the plan, the government in April launched a pilot to distribute free antiretroviral drugs to 3,000 patients in the impoverished Henan province who had contracted HIV through unsanitary blood-selling practices. But without a system to treat and/or monitor the patients-a senior health minister recently estimated that China has fewer than 100 doctors with experience in treating AIDS - the patients were left to follow the complicated drug regimens on their own.

"The elements are simply not in place yet for such a program," says Joel Rehnstrom, the UNAIDS coordinator in China.

Not surprisingly, nearly a fifth of the patients

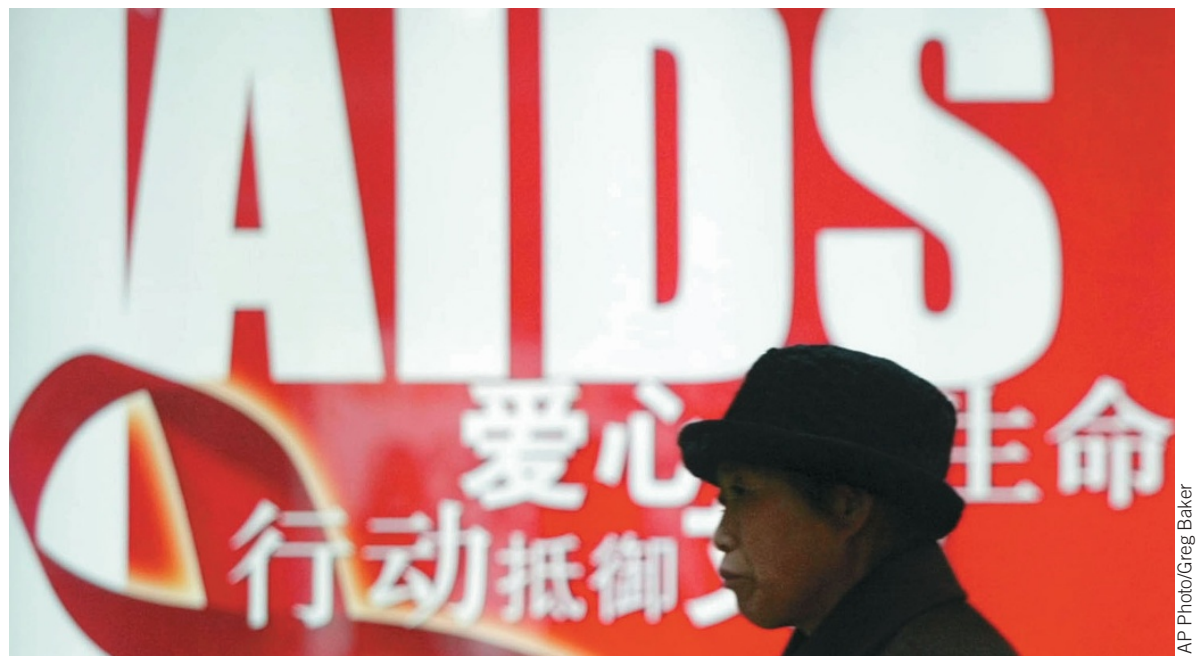

Red alert: China is taking small steps to address its escalating AIDS epidemic. in the pilot program have dropped out because they were not counseled about the side effects. Without adequate instruction, patients will use the drugs erratically, which can lead to the rise of drug-resistant HIV strains, says David Ho of the Aaron Diamond AIDS Research Center in New York. Another problem is that China is limited to using locally produced off-patent drugs such as nevirapine, ddI and AZT. "Their options are somewhat limited," says Ho. "They have the drugs to make one cocktail, and if it doesn't work, they don't have a backup."

Experts say the pilot program may be premature, but are eager to see it get off its feet. In mid-October, the UN Global Fund gave the scheme a financial boost with a five-year, \$98 million grant. The goal is eventually to provide free antiretroviral therapy to all HIV/AIDS patients who cannot afford it.

\section{AIDS infections, deaths hit record high in 2003}

More people became infected with HIV and died from AIDS in 2003 than ever before, according to a new report from the United Nations. A few nations are finally beginning to pay attention and are changing their policies to address the rising numbers.

Approximately 5 million people were infected with HIV in 2003, bringing the total number of people with HIV/AIDS to 40 million worldwide, including about 2.5 million children under 15, according to the report. About 3 million people died from AIDS in 2003. The highest numbers were in sub-Saharan Africa, followed by the Asia/Pacific region, primarily India and China.

To combat the epidemic, India says it hopes by April to begin providing free antiretroviral drugs (ARVs) to its patients. By the end of 2004, each of South Africa's 50 health districts would also have at least one center distributing free ARVs, according to that country's government. Both announcements mark major shifts in the nations' AIDS policies.

Meanwhile, the World Health Organization's ' 3 by 5 ' initiative, which promises to deliver ARVs to 3 million people by 2005 , called for countries to train 100,000 workers and treat patients with four combinations of ARVs.

Aparna Surendran, New York
But even if there are available drugs, notes Jing Jun, professor of sociology and public policy at Tsinghua University in Beijing, only 40,000 of the country's estimated 1 million cases are officially diagnosed. Until there is greater public confidence in health care and less fear of stigma, Jing says, people will be reluctant to come forward for voluntary testing.

Recent months have seen other political milestones in China's stance toward AIDS. In late November, state-sanctioned ads promoting condoms for AIDS prevention began appearing on national television. Condom ads appeared briefly in 1999, but were quickly banned for violating obscenity laws. On 10 November, Tsinghua University in Beijing, one of the country's most prominent schools, hosted a highly publicized summit with prominent participants, including former US president Bill Clinton.

And on 1 December, World AIDS Day, Chinese Premier Wen Jiabao made a televised visit to AIDS patients, marking the first public gesture of acknowledgment from the highest levels of central government.

AIDS activists have praised the government's increasing efforts to target high-risk groups, but say there is a desperate need to educate the general public. Awareness of AIDS is extremely low, particularly in rural areas, they add, and risk factors such as drug use are increasing.

"We have a window of opportunity for the next two to three years to avoid a catastrophic epidemic," says Tsinghua's Jing. "My gut feeling is that key players in the government realize that there is this chance now. If they miss it, we will pay a very high price."

I-han Chou, Tokyo 